\title{
Cue reliability, salience and early comprehension of agreement: Evidence from Greek
}

\author{
Panagiotis KENANIDIS ${ }^{1 \star}$, Vicky CHONDROGIANNI², Géraldine LEGENDRE³, \\ and Jennifer CULBERTSON ${ }^{2}$ \\ ${ }^{1}$ Chair of Language and Cognition, Department of English and American Studies, Friedrich-Alexander- \\ Universität Erlangen-Nürnberg, Erlangen, Germany, ${ }^{2}$ School of Philosophy, Psychology and Language \\ Sciences, University of Edinburgh, Edinburgh, United Kingdom, and ${ }^{3}$ Department of Cognitive Science, \\ Johns Hopkins University, Baltimore, Maryland, USA. \\ ${ }^{\star}$ Corresponding author. Department of English and American Studies, Friedrich-Alexander-Universität \\ Erlangen-Nürnberg, Bismarckstraße 1, 91054 Erlangen, Germany. E-mail: panos.kenanidis@fau.de
}

(Received 18 September 2019; revised 27 April 2020; accepted 9 September 2020;

first published online 20 October 2020)

\begin{abstract}
Previous studies across languages (English, Spanish, French) have argued that perceptual salience and cue reliability can explain cross-linguistic differences in early comprehension of verbal agreement. Here we tested this hypothesis further by investigating early comprehension in Greek, where markers have high salience and reliability (compared to Spanish and English) predicting early comprehension, as in French. We investigated two and three-year-old Greek-speaking children's ability to distinguish third person singular and plural agreement in a picture-selection task. We also examined the frequency of these morphemes in child-directed speech to address input effects. Results showed that three-year-olds are sensitive to both singular and plural agreement, earlier than children acquiring English and Spanish, but later than French, and despite singular agreement being more frequent than plural agreement in the child corpus. These findings provide further support for the role of salience and reliability during early acquisition, while highlighting a potential effect of morpheme position.
\end{abstract}

Keywords: cue reliability; Greek; language comprehension; perceptual salience; verbal agreement

\section{Introduction}

Morphological dependencies - like agreement between the subject and the verb - are widespread in language and their acquisition is an important developmental milestone (Morgan, Barrière \& Woll, 2006). However, they are a complex phenomenon and therefore represent a challenge early on in development. In particular, dependencies like agreement require children to notice (often subtle) variations in the form of one word, which depend on the form of another word, or on the meaning being expressed. Accordingly, a number of studies have found that

(C) The Author(s), 2020. Published by Cambridge University Press. This is an Open Access article, distributed under the terms of the Creative Commons Attribution licence (http://creativecommons.org/licenses/by/4.0/), which permits unrestricted re-use, distribution, and reproduction in any medium, provided the original work is properly cited. 
English-acquiring children do not successfully comprehend verbal agreement in the third person (e.g., The ducks swim vs. the duck swims) ${ }^{1}$ until as late as five years (De Villers \& Johnson, 2007; Johnson, de Villiers \& Seymour, 2005). Similar findings have been reported for Xhosa (Gxilishe, Smouse, Xhalisa \& de Villiers, 2009), Spanish (Gonzalez-Gomez, Hsin, Culbertson, Barrière, Nazzi \& Legendre, 2017; Pérez-Leroux, 2005) and German (Brandt-Kobele \& Höhle, 2010). In contrast, a number of studies reveal that accurate production of verbal agreement comes substantially earlier - between 1;6 and 3;10 (Brown, 1973 in English; Montrul, 2004 in Spanish; Poeppel \& Wexler, 1993 in German). This production-comprehension asymmetry contradicts the traditional view that comprehension precedes production (Fraser, Bellugi \& Brown, 1963). Overall, these findings have led to the hypothesis that the comprehension of verbal agreement is universally late (Johnson et al., 2005; Pérez-Leroux, 2005). However, recent work suggests that learning trajectories might be highly sensitive to specific features of morphophonology present in the language.

\section{Differences in the comprehension of verbal agreement across languages}

The idea that comprehension of verbal agreement is universally late was challenged by Legendre, Barrière, Goyet and Nazzi (2010), who studied the acquisition of verbal inflection in French-speaking children between ages 2-2;6. They explored the prefixal agreement subsystem in Spoken French (Culbertson, 2010; Miller, 1992), expressed by subject clitic agreement markers for the third person singular $(i l)$ and plural $(i l s){ }^{2}$ While orthographically distinct, the third person singular and plural prefixal markers are typically homophonous because the final -s of $i l s$ is silent. However, they are obligatorily pronounced differently when followed by vowel-initial verbs. In this case, a phonological link between the final consonant of the third person plural marker and the initial vowel of the verb (liaison) results in the pronunciation /iz/ or /ilz/. In two experimental tasks targeting comprehension, one using pointing and the other preferential looking, Legendre et al. (2010) investigated whether children were able to match auditorily presented sentences with short dynamic videos using a subject number cue. An example sentence is shown in (1) below. The results showed that by 2;6 children succeed in both tasks.

\section{(1) a. Il-embrasse le 'gef He kisses the 'gef, \\ b. Ils-embrassent le 'tak' They kiss the 'tak'}

Barrière, Goyet, Kresh, Legendre and Nazzi (2016) further showed that French-speaking children's knowledge of agreement morphemes extends to novel verbs. This suggests that their representations of verbal agreement are sufficiently robust and abstract to allow generalization. In contrast to English and other languages, the agreement system in French therefore appears to be acquired early.

\footnotetext{
${ }^{1}$ In a typical sentence of English, an overt subject (pro)noun will also provide a cue to number, however sentences like "The ducks swim" are designed to obscure the final $-\mathrm{s}$ of a subject noun, and therefore test directly the comprehension of verbal number agreement.

${ }^{2}$ See Koulaguina, Legendre, Barrière, Menu, Sivakumar \& Nazzi (2018) for evidence of later acquisition of the suffixal verbal agreement system in French (though at three years of age, this is still earlier than other languages studied).
} 
However, Legendre et al.'s (2010) experimental design differed in a number of ways from previous studies examining comprehension of verbal agreement. First, they used dynamic visual stimuli instead of static pictures, potentially increasing the salience of the verb and the acting subject. Second, novel objects in the scenes were labeled by pseudo-words in order to neutralize the effects of children's knowledge of nouns (Valian, Prasada \& Scarpa, 2006). This would also prevent children from interpreting plural auditory stimuli as referring to both videos displayed on the screen (e.g., The boys kiss the doll; The boy kisses the ball) (cf. Johnson et al., 2005). These modifications aimed to minimize any incidental factors that could affect children's performance, and instead highlight any language specific properties modulating comprehension. Holding the stimuli and procedure constant, Legendre, Culbertson, Zaroukian, Hsin, Barrière and Nazzi (2014) reinvestigated comprehension in English and Spanish-speaking children. The results largely replicated the findings obtained by previous studies: English-speaking children aged between 2;4 and 3;10 showed no signs of comprehension, and Spanish-children as old as age 3;11 succeeded in the plural condition only. ${ }^{3}$ These results confirm that verb agreement is not universally late, but instead depends on the language.

Legendre et al. (2014) propose that cross-linguistic differences in the developmental trajectory of verbal agreement acquisition are driven primarily by morphophonological differences in the agreement systems themselves. In particular, they point to two critical features: perceptual salience (how easily the cue is perceived), and cue reliability (the degree to which the presence of a cue correlates with a given semantic interpretation; e.g., Bates \& MacWhinney, 1987). In terms of perceptual salience, the French third person plural marker $/ \mathrm{z} /$ is likely superior to the Spanish third plural $/ \mathrm{n} /$ (nada- $n$ 'they swim') and the English third singular /s/. The /z/ marker is found either inter-vocalically or prevocalically (ils arrivent 'they arrive' is realized as /izariv/ or /ilzariv/, depending on the register), leading to higher acoustic salience (Benkí, 2003, Redford \& Diehl, 1999). By contrast, both the Spanish /n/ and the English /s/ appear word-finally, either in post-vocalic position or consonant-adjacent (e.g., 'nadan', 'brings'). Legendre et al. (2014) also point out that strident fricatives like /s,z/ are in general more salient than other consonants, which could give an additional boost to the French $/ \mathrm{z} /$.

Legendre et al. (2014) also consider another potential difference between French on the one hand, and English and Spanish on the other. In particular, the French markers are prefixal, and involve a special phonological process (liaison) - both of which may increase the salience of the markers (e.g., Cutler, Hawkins \& Gilligan, 1985). By contrast, English and Spanish (and German) are suffixal. There is evidence from at least one prefixal language, Xhosa, in which comprehension is reported to be late (Gxilishe, de Villiers \& de Villiers, 2007). However, this study uses a different method from Legendre et al. (2010, 2014), and the complex noun class-based agreement system in that language makes it distinct in other ways.

In terms of cue reliability, the French / $\mathrm{z} /$ is MARKEDLY superior to the Spanish and particularly the English markers. It is a highly reliable cue to plurality, marking plural on both verbs and nouns. Moreover, it is extremely rare as a word-initial consonant outside this context. In the case of the Spanish $/ \mathrm{n} /$, there is some ambiguity, as it marks second person plural in most Spanish dialects, but also occurs

\footnotetext{
${ }^{3}$ Though, note that by 3;4 Spanish-speaking children succeed in both singular and plural if the task demands are further reduced (see Gonzalez-Gomez et al., 2017).
} 
very frequently in singular adjectives and nouns. These additional functions possibly make the $/ \mathrm{n} /$ a less reliable marker of plural. The $-s$ morpheme in English is clearly not a reliable cue to the singular: it is used to signal plurality in the nominal domain and also to mark possessives. Thus, children may not rely on its presence in order to resolve singular-plural contrasts in comprehension. Indeed, the particularly low reliability of $-s$ may account for the better performance of Mexican-Spanish children compared to English-speaking children on the comprehension of subject-verb agreement (Legendre et al., 2014; Pérez-Leroux, 2005).

In the present study, we aim to further investigate the role of cue salience and reliability on early comprehension of agreement by focusing on Greek. Following Legendre et al. (2014), the focus of this study is the contrast between the third person singular vs plural forms of the imperfective non-past, in declarative sentences. Greek verbal agreement markers have a number of properties, explained in detail in the next section, which make them unique from the set of languages discussed above. In brief, they are suffixal like English and Spanish (and unlike French), but have high salience and reliability like French (and unlike English and Spanish). If Legendre et al. (2014) are right in claiming that phonological salience and semantic cue reliability are major factors influencing the acquisition of agreement markers cross-linguistically, then early comprehension is predicted.

\section{The Greek verbal agreement system}

Similar to Spanish and Italian, Greek has rich inflectional morphology, with verb inflection being even richer than its noun inflection (Stephany, Voeikova, Christofidou, Gagarina, Kovačević, Palmović \& Hrzica, 2007). Greek verbs are formed by combining a stem and an inflectional suffix that marks each form of the verb for aspect, mood, tense, voice, person and number (Christofidou \& Stephany, 2003; Holton, Mackridge \& Philippaki-Warburton, 1997; Seiler, 1952). In contrast to languages such as English and German, roots are bound and cannot function as words without a co-occurring suffix. Greek regular verbs are divided into two conjugations depending on whether the stress of the verb is on the stem $\left(1^{\text {st }}\right.$ conjugation, e.g., lin-o 'tie-1SG') or on the last syllable ( $2^{\text {nd }}$ conjugation, e.g., agap-ó 'love-1SG'). Here we focus on verbs belonging to the first conjugation, which are more common (Varlokosta, Vainikka \& Rohrbacher, 1998).

There are six inflections in this agreement paradigm, distinctively marking three persons and two numbers without syncretism, as shown in Table 1 for the present tense. Singular suffixes are monosyllabic, while plural suffixes are disyllabic, save for the third person plural where a monosyllabic suffix (-un instead of -une) can be used. As shown in (2), Greek is a pro-drop language, making it distinct from English, but similar to Spanish and French (Culbertson, 2010; Legendre et al., 2014). Most of the features of the subject are fully recoverable from the verb morphology. Indeed, in pro-drop languages, verbal agreement is sometimes considered to have pronominal features (Ackema \& Neeleman, 2007; Alexiadou \& Anagnostopoulou, 1998).

(2) Aní $\gamma$-i tin pórta.

$(\mathrm{He})$ opens the door. 
Table 1. Greek agreement paradigm for the present tense ( $1^{\text {st }}$ conjugation)

\begin{tabular}{lll}
\hline Person & Singular & Plural \\
\hline $1^{\text {st }}$ & -0 & -ume \\
\hline $2^{\text {nd }}$ & - is & -ete \\
\hline $3^{\text {rd }}$ & - i & -un(e) \\
\hline
\end{tabular}

Rich verbal morphology in languages like Italian and Spanish is sometimes claimed to facilitate the early production of verbal forms (Guasti, 1993). This view has been confirmed by previous studies on Greek (Stephany, 1985, 1997; Varlokosta, 2005; Varlokosta et al., 1998). Based on longitudinal data from two Greek monolingual children, Doukas and Marinis (2012) report that subject-verb agreement is produced with high accuracy by the age of three. The most common error before this stage is the overuse of the verbal suffix '-i' (Doukas \& Marinis, 2012; Stephany, 1997; Tsimpli, 1996). Two explanations have been put forward for this pattern. Doukas and Marinis (2012) suggest that the early verbal forms with the suffix '- $\mathrm{i}$ ' correspond to the third person singular and that children substitute first and second person singular forms with the earliest acquired third person singular form, whereas Varlokosta et al. (1998) propose that the overgeneralisation of verbal forms with the suffix ' $-i$ ' is an indication that Greek children use non-finite forms that correspond to the root infinitive forms found in other languages (although see Hyams, 2002 for a counterargument). Doukas and Marinis (2012) also report that singular forms are usually produced before plurals. Overall, these studies suggest that Greek children's development of verbal agreement may be quite early; at the very least they correctly PRODUCE these forms at a young age. As discussed above however, accurate production does not necessarily imply comprehension: studies on English, German and Spanish all show early target-like production (e.g., Brown, 1973; Rice \& Wexler, 1996 in English; Clahsen, 1986; Poeppel \& Wexler, 1993 in German; Gathercole, Sebastián \& Soto, 2002; Montrul, 2004 in Spanish), even though children learning these same languages show late comprehension.

\section{Perceptual saliency and cue reliability of Greek markers}

As summarized above, Legendre et al. (2014) propose that perceptual salience and cue reliability affect the early acquisition of verbal agreement morphemes. Like the suffixal markers in English and Spanish, the Greek markers in the verbal inflectional class studied here are unstressed. However, they are syllabic and do not contain schwa (all vowels are fully pronounced; Nikolopoulos \& Goulandris, 2000). Their phonological weight, therefore, gives them higher acoustic salience compared to mono-segmental suffixes, such as /s/ in English, /n/ in Spanish (and /t/ in German and Dutch; Leonard \& Bortolini, 1998). ${ }^{4}$ The two markers we focus on here are the third

\footnotetext{
${ }^{4}$ Note that verbs in the second conjugation in Greek actually carry stressed on the suffix (e.g. ayap-á-o/ ayap-ó 'love-1SG'), which likely increases their acoustic saliency. However, we do not use this class here for several reasons. First, according to Holton et al. (1997), these verbs are less common and more phonologically complex compared to first conjugation verbs. Second, they seem to be later acquired
} 
singular $-i$ and the third plural $u n(e)$, which are also completely phonologically distinct from one another. Notably, all Greek morphemes are syllabic (in some cases disyllabic) and thus the perceptual salience of the system overall is likely relatively high. Finally, this paradigm features unique forms for each person and number combination in contrast with other languages (Spanish, English, German, Dutch). While Legendre et al. (2014) do not generally focus on the high-level properties of these different agreement systems, they are nevertheless worth noting.

In terms of cue reliability, although Greek has a strict noun-verb distinction, verbs and nouns do share some phonologically identical inflectional suffixes. Specifically, the form used for the first singular, ' $-o$ ', reliably indicates neuter gender in nouns (Varlokosta, 2011; Varlokosta \& Nerantzini, 2013), but also marks other nominal elements (adjectives, pronouns) and the accusative singular of masculine and feminine nouns ending in '-os' that belong to the first (IC1) of the eight inflectional classes in Greek

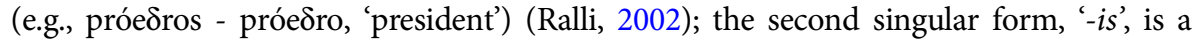
reliable cue for masculine nouns (Varlokosta \& Nerantzini, 2013) and also marks the genitive singular of feminine nouns ending in ' $-i$ ' that belong to IC3 (e.g., arápi a aápis 'love') and the genitive singular, nominative, accusative and vocative plural of feminine nouns belonging to IC4 (e.g., práksi -práksis 'word'); and most relevant here, the third singular form, ' $-i$ ', marks both feminine and neuter nouns. In fact, previous findings suggest that nouns with the suffix ' $-i$ ' are ambiguous between feminine and neuter gender, both for adult (Mastropavlou, 2006; Varlokosta, 2011) and children native speakers (Varlokosta \& Nerantzini, 2013). In addition, the ' $-i$ ' marker indicates the nominative and vocative plural of masculine nouns that belong to

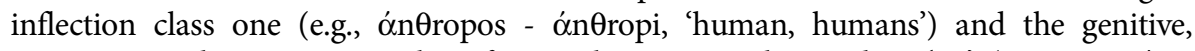
accusative and vocative singular of masculine nouns that end in '-is' (e.g., ma日itís ma $\theta i t i$, 'student') of inflection class two. Therefore, $-i$ has relatively low cue reliability. However, like the French / $\mathrm{z} /$, Greek plural inflections '-ume', '-ete', '-un(e)' are all unambiguous markers of (verbal) plurality; hence the plural markers have high cue reliability.

To summarize, the Greek system in general, and the particular markers we will test in the current study (third singular $-i$ and third plural -un(e)), resemble the French system discussed above in a number of ways. The plural marker has high cue reliability and is highly perceptually salient. The third person singular marker $-i$ has lower cue reliability but it is syllabic, hence inherently salient. Therefore, if cue salience and reliability are the driving forces allowing French subject-verb agreement to be acquired early, then Greek children should show relatively early comprehension. The stronger cue reliability of the $-u n(e)$ marker additionally predicts the possibility of higher accuracy for plural than for singular subject-verb agreement.

The main aim of the current study was to test the hypothesis that specific properties of agreement systems - specifically, perceptual salience and cue reliability - hinder or facilitate the mastery of verbal agreement. As outlined above, this hypothesis predicts early comprehension of third person verbal number agreement in Greek. We investigate this in Greek-speaking two and three-year-olds by asking whether they are able to correctly map between videos featuring actions by one or two agents, and

both in terms of the person-number combinations and the tense-aspect-mood categories that are used productively (Christofidou \& Stephany, 2003). Last, there is (dialectal and individual) variation in the

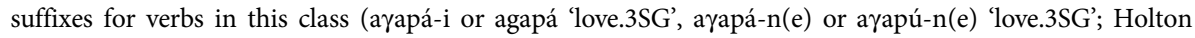
et al., 1997). 
stimuli instantiating singular and plural verbal agreement. Importantly, we adopt the experimental methodology used by Legendre et al. (2014) in order to obtain comparable results to earlier studies in English, French and Spanish.

Our second aim was to evaluate whether the frequency of third person singular and plural agreement markers in the Greek child-direct speech could account for children's performance in our comprehension task. Previous studies investigating the acquisition of inflectional morphology have shown that the higher the input frequency of individual inflected forms is, the more likely they are to be produced correctly (Aguado-Orea \& Pine, 2015; Maslen, Theakston, Lieven \& Tomasello, 2004; Räsänen, Ambridge \& Pine, 2016). On the other hand, studies focusing on comprehension of verbal agreement have reported mixed results. While some studies suggest that asymmetrical patterns of singular and plural comprehension may be driven by input frequency (e.g., in Chilean Spanish; Childers, Fernandez, Echols \& Tomasello, 2001), others find the opposite: comprehension of both singular and plural in French despite much lower frequency of plurals in the input (Barrière et al., 2016; Legendre et al., 2010; Nazzi, Barrière, Goyet, Kresh \& Legendre, 2011). To preview, we find that, as for French, frequency in the input does not appear to drive comprehension of verbal number agreement in Greek.

\section{Testing comprehension of verbal number agreement in Greek Method}

\section{Participants}

Twenty two-year-old $(\mathrm{M}=31.53$, range $=2 ; 2.27-2 ; 11.27, \mathrm{SD}=3,1)$ Greek-speaking monolingual children and twenty-eight three-year-old $(M=43.02$, range $=3 ; 2.02-$ $3 ; 11.14, \mathrm{SD}=3,4)$ Greek-speaking monolingual children were tested in the study. All children were selected on the basis of having no documented developmental disorder. Participants were tested in Athens and in Larissa, Central Eastern Greece. Two children were tested but excluded from the study due to their refusing to participate in the experiment (1) or failing to understand the instructions (1).

\section{Visual stimuli}

The visual stimuli that were used here were the same as those originally developed by Legendre et al. (2010). In these videos two eight-year-old boys were filmed performing a simple action on different objects that were carefully selected to be unfamiliar to children. The two boys performed ten simple actions and for each of the actions, either one boy performed alone (singular), while the other boy was standing next to him, or both of the boys performed the action together (plural), simultaneously and on the same object (see Figure 1). Twenty videos were filmed in total, half of which were singular, while the other half were plural. Eight of the ten original videos were used in the present study (see below), using the experimental procedure previously developed for Mexican-Spanish children (Legendre et al., 2014).

The unfamiliar objects in the videos were different for each activity and the two boys were filmed using two different nonce objects in the singular and plural conditions. Recall that this design aimed to eliminate any possible effects of object nouns, and to block the possibility of interpreting a plural utterance as collectively referring to the entire display (i.e., both pictures/videos). Using two distinct pseudo-words also 


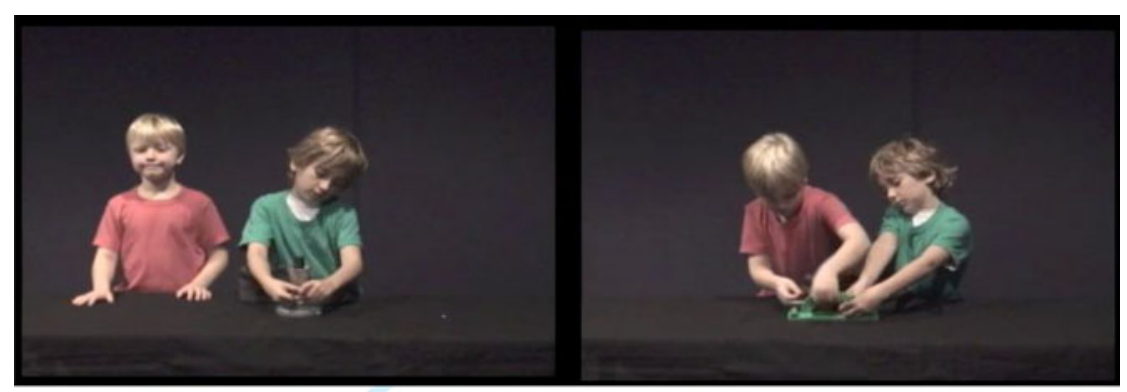

Figure 1. Still images of the video stimuli in the singular (left) and plural conditions (right).

discourages a distributive reading, in which a singular utterance can be interpreted as referring to both the singular video and to ONE of the two subjects in the plural visual stimulus (Kouider, Halberda, Wood \& Carey, 2006). The total number of unfamiliar objects was 16 , as 2 different items were used for each of the eight actions. The duration of all videos was 6 seconds.

Prior to presentation of test trials, a total of four training trials were administrated. These included still images of known objects (a cat, a dog, an apple, a banana) that were easily recognized by the children. Each pair of images was presented for 6 seconds.

\section{Verbal stimuli}

Auditory stimuli were created to describe each of the eight actions that were displayed by the visual stimuli. These actions referred to eight of the verbs that were used in studies with French, Spanish and English-speaking children (Barrière et al., 2016; Gonzalez-Gomez et al., 2017; Legendre et al., 2010, 2014). All verbs used were in the first conjugation class in Greek: anáßo 'switch on',

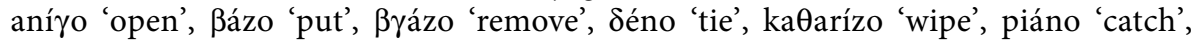
férno 'bring'. The video corresponding to 'take out' in previous studies was described using 'put' in Greek because 'remove' and 'take out' are synonyms in Greek. This matches the video equally well, as the boys are shown putting an object on a table.

Verbs were embedded in short sentences, with a transitive verb + determiner + pseudo noun structure, an example of which can be seen in (3). The monosyllabic third person plural $-u n$ was used instead of the bisyllabic -une, as the use of $-e$ is generally optional for most Greek speakers. Null-subject sentences were created in order to mask the number marking on the subject and to provide only one cue to number from the verb (following Legendre et al., 2014 for Spanish). Pseudo-nouns were used to describe the unfamiliar object as it would allow direct comparison with the results of the previous studies (Legendre et al., 2010, 2014). These pseudo-nouns were designed to be disyllabic and contain early acquired consonants (Mennen \& Okalidou, 2007). Some of the pseudo-words were taken from Revithiadou and Lengeris (2016), and the remainder were created using the procedure outlined in Varlokosta (2011). Specifically, novel nouns (e.g., 'tepa') were created by changing two phonemes of real nouns (e.g., kupa 'cup') in order to make the two words differ sufficiently. 
(3) a. $\Delta$ én-i to káfo.

He ties the 'kafo'.

b. $\Delta$ én-un to káfo

They tie the 'kafo'.

Following Legendre et al. (2014), the short sentences were embedded in indirect questions, as in (4), to prompt children to choose one of the videos. These verbal stimuli were recorded by a female native Greek speaker using child-directed speech. The sentences were produced with a noticeably accentuated pitch and at a normal speed to facilitate children's attention and comprehension during the task.

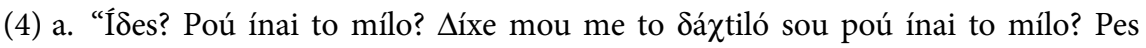
mou poú ínai to mílo".

"Did you see? Where is the apple? Show me with your finger where the apple is. Tell me where the apple is.".

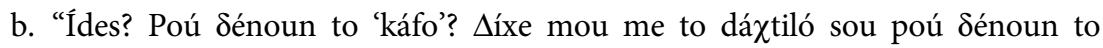
'káfo'? Pes mou poú Sénoun to 'káfo'."

"Did you see? Where are they tying the 'kafo'? Show me with your finger where they are tying the 'kafo'. Tell me where they are tying the 'kafo"'.

\section{Procedure}

The procedure followed for testing children was largely the same as in the pointing version of the experiment reported for Spanish-speaking children in Legendre et al. (2014). All participants were tested individually in a quiet room within their kindergarten. A member of the kindergarten's staff was always present. The child was seated in front of a laptop computer with a 17" screen where the visual stimuli were displayed, while the experimenter was seated to the immediate right of the child. A second coder, blind to the condition (singular or plural) on each trial, was sitting behind the screen and recorded whether each child was pointing at the right or at the left video.

Each child was told that some images would be displayed on the screen and she should select one of them according to the description given by the audio stimuli. The session started with the training trials. Up to four training trials were presented to set up the pointing game. Note that the training trials did not involve agreement, but were only intended to familiarise participants with the pointing task. A fixation image of a smiley face was displayed to center the child's attention. Once the child looked at the center of the screen two familiar objects were presented simultaneously and in silence on each side of the screen for 6 seconds. When the screen turned black, the experimenter named one of the objects and prompted the child (as in $4 \mathrm{a}$ ) to point to it before the images reappear on the screen for 6 more seconds. If the child failed to point during the first seconds, the experimenter repeated the invitation to point. Once the child responded, a 3-second video of a dance performed by the two boys featured in the test videos was displayed at the side of the matching training image. The same procedure was followed for the eight test trials, with sentences containing known verbs and novel objects (as in $4 \mathrm{~b}$ ). For half of the trials, the target video was the singular one (one boy), while for the other half the audio stimulus corresponded to the plural 


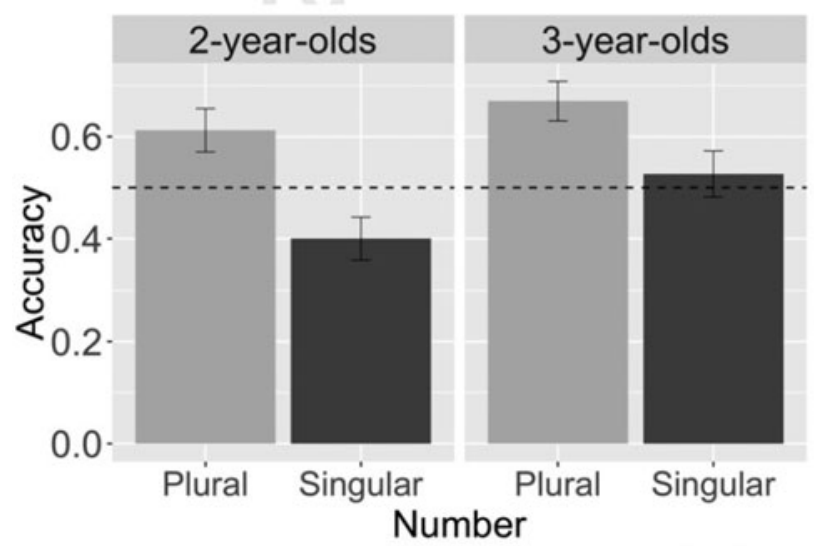

Figure 2. Mean percentage of pointing toward the target video at test across singular and plural trials for both age groups. Error bars show standard error on by-participant means. Dotted line indicated chance-level accuracy.

video (two boys). The side where the matching video was displayed was counterbalanced within participants for each condition.

\section{Coding}

Coding of children's responses was carried out online by the experimenter sitting next to the child, who clicked on the image selected by the participant, and at the same time by a blind coder sitting behind the screen. There was disagreement on only two trials across 48 participants between the coders and it was resolved after discussion between the two coders. Accuracy scores for each child were then calculated as percentages of pointing towards matching videos.

\section{Results}

Figure 2 shows the mean accuracy scores across singular and plural trials for the two and three-year-olds.

The data were analyzed using logistic regression, ${ }^{5}$ with age group (two- vs. threeyear-olds), condition (singular v. plural) and their interaction as predictors (sum coded). The model revealed a main effect of condition $(\beta=0.37 \pm 0.11, p=<0.001)$. However, the main effect of age was only marginally significant $(\beta=-0.19 \pm 0.11$, $p=0.07)$ with no significant interaction between condition and age $(\beta=0.07 \pm 0.11, p=$ 0.53). To summarize, while there is a marginal trend for the two-year-olds to perform worse, the effect of condition is independent of age group. Both groups performed above chance for plural trials (2-year-olds: $\beta=0.46 \pm 0.23, p=0.05$ ); three-year-olds: $\beta=$

\footnotetext{
${ }^{5}$ Note that while Legendre et al. (2014) use ANOVA, this is not in general the best way to analyze binary response data (e.g. see Agresti, 2002; Jaeger, 2008). Rather, the default choice here would be mixed-effects logistic regression. However, here we do not have a sufficient number of trials per participant to run mixed-effects analysis ( 4 singular and 4 plural trials per participant), therefore we run standard logistic regression models in $\mathrm{R}$ ( $\mathrm{R}$ Core Team, 2018).
} 


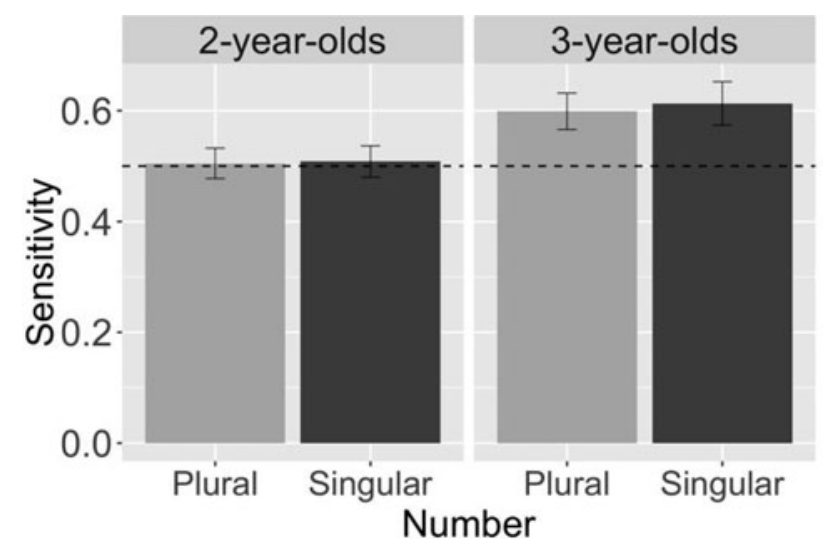

Figure 3. Mean sensitivity across singular and plural trials for both age groups. Error bars show standard error on by-participant means. Dotted line indicated chance-level.

$0.71 \pm 0.20, \quad p<0.001)$, and neither group performed above chance for singulars (2-year-olds: $\beta=-0.41 \pm 0.23, p=0.08$ ); 3-year-olds: $\beta=0.11 \pm 0.19, p=0.57$ ).

Following previous studies on comprehension of subject-verb agreement (Barrière et al., 2016; Gonzalez-Gomez, Hsin, Barrière, Nazzi \& Legendre, 2017; Johnson et al., 2005), children's SENSITIVITY to singular and plural stimuli was also analysed. Sensitivity adjusts accuracy using an estimate of children's bias for a particular stimulus - in this case, singular or plural pictures. Here, there is a tendency for children in both age groups to choose the plural picture (regardless of the verbal stimulus). ${ }^{6}$ Analysis of sensitivity rather than accuracy scores therefore allows us to eliminate this bias. Two sensitivity scores, one for singular and one for plural items, were calculated for each participant by dividing the times they chose the video matching the auditory stimuli by the total times they chose that video. Sensitivity scores for both age groups are shown in Figure 3. Analysis using ANOVA revealed a significant effect of age $(F(1)=$ $8.23, p=0.005)$ but no effect of condition $(F(1)=0.08, p=0.78)$. These results suggest that a bias for choosing the plural picture may have led to the apparent difference between singular and plural in our accuracy analysis above. Correcting for this bias in both age groups suggests instead that three-year-olds are sensitive to both singular and plural agreement, while two-year-olds are not.

To summarize, the results reported here indicate that by three years of age, children acquiring Greek are sensitive to both singular and plural number agreement. By contrast at the age of two, Greek-acquiring children are not yet sensitive enough to these agreement markers to succeed in this task. Accuracy scores alone suggested better performance for plural in both groups (in fact above chance even at two), but this appears to have been driven by a bias for pointing to the plural scene regardless of the verbal stimulus.

\footnotetext{
${ }^{6}$ This bias appears to be common, at least for these stimuli, and is found to some degree across a number of studies (see e.g., Barrière, Kresh, Aharodnik, Legendre \& Nazzi, 2019; Brandt-Kobele \& Höhle, 2010; Gonzalez-Gomez et al., 2017). Plural videos or pictures provide a greater amount of visual information (two actors performing an action) and, therefore, may tend to attract children's attention more than the singular ones.
} 
Before we discuss how these results fit with the hypothesized role of cue salience and reliability, we first address another factor that has been hypothesized to influence the comprehension of agreement morphemes: input frequency. Although previous studies in French have failed to show a relationship between adult input and child performance (e.g., Barrière et al., 2016; Legendre et al., 2010), frequency effects are argued to play a significant role in children's first language acquisition (Ambridge, Kidd, Rowland \& Theakston, 2015; Theakston, Lieven \& Tomasello, 2003). In line with this idea, Childers et al. (2001) suggested that Chilean Spanish-speaking children's early comprehension of third person singular, but not the plural, were correlated with a singular bias in the adult input. Therefore, it is worth determining whether any such asymmetries exist in Greek child-directed speech, and if so whether this might explain children's apparent bias for plural.

\section{Corpus analysis}

We examined a potential relationship between the frequencies of lexical items in child-directed speech and children's performance in the comprehension task by extracting all the adult input from the two Greek corpora available in the CHILDES Database (MacWhinney, 2000), namely the Stephany (1997) and the Doukas (2011) corpora.

\section{Method}

For this analysis, we generated a frequency list of the words produced by the adults in both corpora. The Stephany corpus contains spontaneous speech data by Greek-speaking mothers and grandmothers of four monolingual Greek children: Mairi (1;9.18-2;9.20), Janna (1;10.25-2;11.27), Spiros $(1 ; 8.22-1 ; 9.11)$ and Maria (2;3.7-2;9.17). The data were collected between 1971 and 1974. The Doukas corpus is comprised of speech data from well instructed relatives of two monolingual Greek children, Maria $(2 ; 0.24-2 ; 8.27)$ and Eve $(1 ; 7.15-2 ; 11.11)$. The data were collected in 1998 and between 2004 and 2005, respectively.

From the frequency list generated, first, we manually annotated all the verbs for conjugation, person, number and morphology and then calculated the frequencies and proportions of occurrence of persons across the singular and plural number. All verbs with non-passive morphology from the first and second conjugation were coded, as it would allow us to get a good overall picture of the forms that Greek-speaking children are exposed to. Because all Greek verbs with passive morphology and/or past tense have different inflectional forms for the third person

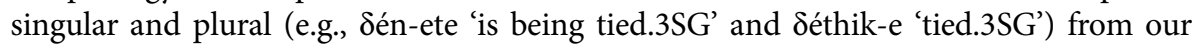
experimental target forms in the present tense, $-i$ and $-u n(e)$, they were excluded from the list. Finally, following Ambridge et al.'s (2015) claim that frequency effects should be tested at the level of individual lexical items, we calculated the token

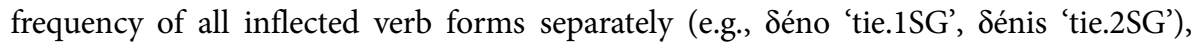
instead of focusing on lemma frequencies. The final list of adult input consisted of 720 types and 5,686 word tokens (type - token ratio: $12.66 \%$ ).

\section{Results}

An overview of the results is presented in Table 2. Overall, Greek-speaking children are systematically exposed to a large proportion of singular inflections compared to the 
Table 2. Frequency and proportion of occurrence of the verbal agreement morphemes in child-directed speech in two CHILDES corpora (Doukas, 2011; Stephany, 1997).

\begin{tabular}{lrrrr}
\hline & \multicolumn{2}{c}{ 1st Conjugation } & \multicolumn{2}{c}{ 2nd Conjugation } \\
\hline $1 S G$ & 669 & $(11.77 \%)$ & 95 & $(1.67 \%)$ \\
\hline $2 S G$ & 1657 & $(29.14 \%)$ & 222 & $(3.90 \%)$ \\
\hline $3 S G$ & 1463 & $(25.73 \%)$ & 386 & $(6.79 \%)$ \\
\hline $1 P L$ & 780 & $(13.72 \%)$ & 43 & $(0.76 \%)$ \\
\hline $2 P L$ & 22 & $(0.39 \%)$ & 4 & $(0.07 \%)$ \\
\hline $3 P L$ & 310 & $(5.45 \%)$ & 35 & $(0.61 \%)$ \\
\hline
\end{tabular}

plural ones, in both conjugations. Moreover, the third person plural form -un is one of the least produced forms of the first conjugation (5.45\%), whereas the third person singular $-i$ was the second most frequent morpheme used by Greek-speaking adults (25.73\%).

The results obtained from the corpus analysis fail to reveal any clear relationship between children's performance on the comprehension task and the adult input: the singular bias in child-directed speech revealed by the analysis of two Greek corpora is not reflected in the comprehension results, where sensitivity to the singular and plural forms were the same in both age groups. If anything, the higher unadjusted accuracy scores were higher for plural $-u n$.

\section{General discussion}

The goal of the current study was to test the hypothesis that language-particular properties of verbal agreement explain the developmental time course of comprehension cross-linguistically. Accordingly, we examined the comprehension of verbal number agreement in a language that has not been studied in this respect namely, Greek - which shares some relevant properties with previously studied languages. Following the same experimental methodology employed in a recent series of studies (Legendre et al., 2010; 2014), we tested two- and three-year-olds' ability to match speech stimuli to the appropriate video based on number information expressed by third person agreement markers. The main finding that emerged is that Greek-speaking children succeed in this task at three - showing sensitivity to both singular and plural agreement - but do not yet succeed at two. Note that this result is dependent on adjusting accuracy scores to take into account children's bias for choosing plural pictures. Without this adjustment, children of both age groups appeared to succeed for plural but not singular. We also reported the results of a corpus study of Greek child-directed speech, which revealed that singular forms are much more frequent in the input than plural forms (similar to what was previously reported for French, see Legendre et al., 2010). This suggests that comprehension of number agreement is not obviously driven by the input frequency of individual forms. Below we discuss how our results fit into the picture of agreement acquisition advocated in Legendre et al. (2014).

Starting with our corpus results, we found no evidence for a clear relationship between input frequency and comprehension success. We observed a singular bias in 
terms of input frequency, which has also been observed in a number of other languages (French, Spanish, and English). While this has been invoked as an explanation of a parallel singular bias in child production or comprehension (Childers et al., 2001; Leonard, Caselli \& Devescovi, 2002), comprehension data from French, Spanish, and now Greek show that when children succeed, they are either equally good at singular and plural (French and Greek) or show better performance in the plural (Spanish). These results do not straightforwardly match with the predictions of theories of acquisition which argue that the more frequently learners are exposed to a particular inflected word form, the more likely they are to comprehend it correctly (Theakston et al., 2003; Tomasello, 2003).

The account set out in Legendre et al. (2014) instead argues that specific features of the agreement morphemes in a language can explain how early they are learned. In particular, the higher the salience and reliability of the markers in question, the easier they are for children to comprehend. The Greek morphemes we tested here, third singular $-i$ and third plural $-u n$, are syllabic, and therefore relatively high salience (e.g., compared to English $\varnothing$ and $-s$, or Spanish $\varnothing$ and $-n$ ). Further, as with the French plural $-z$, the Greek plural $-u n$ is a highly reliable cue to verbal plurality (compared to e.g., English $-s$ and Spanish $-n$ which are less reliable). We therefore predicted that comprehension of these forms should be relatively early in Greek. This was partially confirmed: whereas English-speaking children between the ages of 2;4 and 3;10 show no signs of comprehension in this same task, and Spanish-children as old as 3;11 succeeded in the plural condition only (Legendre et al., 2014), Greek-acquiring children are sensitive to both singular and plural at around 3;2 years of age. They do not, however, succeed in the task at 2;6, whereas French children aged 2;6 do (Barrière et al., 2016; Legendre et al., 2010). In general, these results are consistent with Legendre et al. (2014): increased salience and reliability lead to relatively early comprehension success for Greek-acquiring children. That French children nevertheless succeed earlier suggests there are yet differences in the two systems that affect children's acquisition patterns.

There are two obvious such differences between French and Greek: prefixal versus suffixal position, and the special phonological process of liaison which impacts processing of the agreement markers in French. Compared to prefixal agreement, the processing of suffixal agreement could be hindered because it comes later in the stimulus (Cutler et al., 1985). This would predict that, all things equal, children acquiring other prefixing languages should succeed in this task earlier. The only other prefixal language in which early comprehension of verbal agreement has been studied is Xhosa, a pro-drop Bantu language in which the agreement markers are found pre-verbally. In a picture selection task, four- to six-year-old Xhosa-speaking children did not comprehend either singular or plural verbal agreement (Gxilishe et al., 2009). However, as we noted earlier, this study uses a different design, and different stimuli from the results reported here and for French, English, and Spanish by Legendre and colleagues. This makes it difficult to compare the results directly. Further, the agreement system in Xhosa is much more complex: agreement markers are determined by noun class, with 15 classes total (8 singular and 7 in plural). It may be that this system is later acquired because children must simultaneously learn to condition agreement on semantic and phonological features of noun subjects.

However, another possibility is that suffixal agreement positioning poses a difficulty that is largely specific to the task we use. In this task, the verb is immediately followed 
by a novel noun. Interestingly, Gonzalez-Gomez et al. (2017) used the same design but replaced the novel object noun with a generic el objecto 'the object' in the verbal stimuli. This resulted in lowering the age of comprehension of Spanish subject-verb agreement. According to the authors, one possible interpretation of this result is that the Spanish agreement suffixes are positioned closer to the novel nouns compared to French agreement prefixes and may hinder children's ability to detect agreement by introducing an additional cost associated with processing the novel nouns, thus masking Spanish-speaking children's comprehension. Further, other studies, e.g., of English, have emphasized the role of sentence-position effects. In a preferential listening task with English-learning children aged between 1;10 and 2;3, Sundara, Demuth and Kuhl (2011) found that the perception of the verbal $-s$ was higher when it was in a sentence-final ('Now he cries') rather than when it was in a sentence-medial position ('He cries now').

Picture-selection tasks are thought to pose high processing demands on children's linguistic and non-linguistic cognitive skills (Höhle, Berger, Müller, Schmitz \& Weissenborn, 2009). Therefore, the effects of perceptual salience and cue reliability may interact with effects of positioning. When an agreement marker is phonologically salient and reliable, it is more likely to draw children's attention and reduce their information processing load. This would allow Greek-acquiring children to overcome positional effects and succeed in the task earlier than in English and Spanish. But comprehension would still be later than in French, where position is early in the stimulus, and not in close temporal proximity to a pseudo-word (with processing demands of its own). Legendre et al. (2014) further suggest that the phonological process of liaison may further increase French children's sensitivity to prefixal agreement, above and beyond other features of the system. Briefly, the argument is that liaison - which in this case resyllabifies the final consonant of the prefix into the onset of the verb-must be undone in order to access the lexical meaning of the verb. This is a crucial part of processing both verbs and nouns in French, and there is evidence that children master it very early (e.g., Babineau \& Shi, 2011). Having to attend to the prefixes in this way may, somewhat counterintuitively, make these forms even more salient to children.

To summarize, this study provides additional support for the role of languagespecific agreement features in driving children's comprehension. The Greek third person singular and plural morphemes targeted here have relatively high salience and cue reliability. Thus, we predicted that they should be acquired earlier than those tested in English and Spanish. Our prediction was borne out: we found that Greek-acquiring three-year-old children are able to choose videos of actions matching a singular and plural verbal stimulus. However, like English and Spanish, the Greek morphemes are suffixal. Here we have suggested that the effect of positioning may interact with salience and reliability to explain why, unlike French children at 2;6, Greek children around this same age fail at the task. Future work is needed to determine exactly which of the mechanisms outlined above explains this difference.

Acknowledgements. We are very grateful to the daycare centers Xamogelo and Pavlopoulos Schools, to the children who participated in our study and their parents. We also thank Eirini Skopelitou for her assistance with the collection of data, the Municipality of Larissa (Greece) and Mr D. Deligiannis, for allowing us to collect data from children attending two local daycare centers. 


\section{References}

Ackema, P., \& Neeleman, A. (2007). Restricted pro drop in early modern Dutch. The Journal of Comparative Germanic Linguistics, 10(2), 81-107.

Aguado-Orea, J., \& Pine, J. M. (2015). Comparing different models of the development of verb inflection in early child Spanish. PLoS ONE, 10(3), 1-21.

Agresti, A. (2002). Categorical Data Analysis. Second Edition. Hoboken, New Jersey: John Wiley \& Sons.

Alexiadou, A., \& Anagnostopoulou, E. (1998). Parametrizing AGR: Word order, V-movement, and EPP-checking. Natural Language and Linguistic Theory, 16(3), 491-540.

Ambridge, B., Kidd, E., Rowland, C. F., \& Theakston, A. L. (2015). The ubiquity of frequency effects in first language acquisition. Journal of Child Language, 42(2), 239-273.

Babineau, M., \& Shi, R. (2011). Processing of French liaisons in toddlers. In N. Davis, K. Mesh, \& H. Sung (Eds.), Proceedings of the 35th Boston University Conference on Language Development (pp. 25-37). Somerville, MA: Cascadilla Press.

Barrière, I., Goyet, L., Kresh, S., Legendre, G., \& Nazzi, T. (2016). Uncovering productive morphosyntax in French-learning toddlers: a multidimensional methodology perspective. Journal of Child Language, 43 (5), 1131-1157.

Barrière, I., Kresh, S., Aharodnik, K., Legendre, G., \& Nazzi, T. (2019). The comprehension of 3rd person singular by NYC English-speaking pre-schoolers. In T. Ionin \& M. Rispoli (Eds.), Three streams of generative language acquisition research. Selected papers from the 7th meeting of Generative Approaches to Language Acquisition-North America, University of Illinois at Urbana-Champaign (Vol. 63, pp. 7-33). Amsterdam, The Netherlands / Philadelphia, PA: John Benjamins Publishing Company.

Bates, E., \& MacWhinney, B. (1987). Competition, variation, and language learning. In B. MacWhinney (Ed.), Mechanisms of language acquisition (pp. 157-193). Hillsdale, NJ: Erlbaum.

Benkí, J. R. (2003). Analysis of English nonsense syllable recognition in noise. Phonetica, 60(2), 129-157.

Brandt-Kobele, O. C., \& Höhle, B. (2010). What asymmetries within comprehension reveal about asymmetries between comprehension and production: The case of verb inflection in language acquisition. Lingua, 120(8), 1910-1925.

Brown, R. (1973). A first language: The early stages. Cambridge, MA: Harvard University Press.

Childers, J., Fernandez, A. M., Echols, C., \& Tomasello, M. (2001). Experimental investigations of children's understanding and use of verb morphology: Spanish- and English-speaking 2 1/2- and 3-year-old children. In M. Almgrem, A. Barreña, M. J. Ezeizabarrena, I. Idiazabal, \& B. MacWhinney (Eds.), Research on Child Language Acquisition: Proceedings of the 8th Conference of the International Association for the Study of Child (pp. 104-127). Somerville, MA: Cascadilla Press

Christofidou, A., \& Stephany, U. (2003). Early phases in the development of Greek verb. In D. Bittner, W. Dressler, \& M. Kilani-Schoch (Eds.) Development of Verb Inflection in First Language Acquisition: A Cross-Linguistic Perspective (pp. 89-130). Berlin: Mouton de Gruyter.

Clahsen, H. (1986). Verb inflections in German child language: Acquisition of agreement markings and the functions they encode. Linguistics, 24, 79-121.

Culbertson, J. (2010). Convergent evidence for categorical change in French: From subject clitic to agreement marker. Language, 86(1), 85-132.

Cutler, A., Hawkins, J., \& Gilligan, G. (1985). The suffixing preference: a processing explanation. Linguistics, 23, 723-758.

De Villiers, J. G., \& Johnson, V. E. (2007). The information in third-person /s/: acquisition across dialects of American English. Journal of Child Language, 34(1), 133-158.

Doukas, T. (2011). Acquisition of the verbal domain in child Greek evidence from a new child Greek corpus (Doctoral dissertation, University of Reading).

Doukas, T., \& Marinis, T. (2012). The acquisition of person and number morphology within the verbal domain in early Greek. University of Reading. Language Studies Working Papers, 4, 15-25. <https:// childes.talkbank.org/access/Other/Greek/Doukas.html>

Fraser, C., Bellugi, U., \& Brown, R. (1963). Control of grammar in imitation, comprehension, and production. Journal of Verbal Learning and Verbal Behavior, 2(2), 121-135.

Gathercole, V. C. M., Sebastián, E., \& Soto, P. (2002). The emergence of linguistic person in Spanish-speaking children. Language Learning, 52, 679-722. 
Gonzalez-Gomez, N., Hsin, L., Barrière, I., Nazzi, T., \& Legendre, G. (2017). Agarra, agarran: Evidence of early comprehension of subject-verb agreement in Spanish. Journal of Experimental Child Psychology, $160,33-49$.

Guasti, M. T. (1993). Verb syntax in Italian child grammar: Finite and nonfinite verbs. Language Acquisition, 3(1), 1-40.

Gxilishe, S., de Villiers, P., \& de Villiers, J. (2007). The acquisition of subject agreement in Xhosa. In A. Belikova, L. Meroni, \& Mari Umeda (Eds.) Proceedings of the Conference on Generative Approaches to Language Acquisition (GALANA) (Vol. 2, pp. 114-23). North America Somerville: Cascadilla Press.

Gxilishe, S., Smouse, M., Xhalisa, T., \& De Villiers, J. (2009). Children's insensitivity to information from the target of agreement: The case of Xhosa. In J. Crawford, K. Otaki, \& M. Takahashi (Eds.), Proceedings of the 3rd conference on generative approaches to language acquisition North America (pp. 46-53). Somerville, MA: Cascadilla Press.

Höhle, B., Berger, F., Müller, A., Schmitz, M., \& Weissenborn, J. (2009). Focus particles in children's language. Production and comprehension of auch 'also' in German learners from 1 year to 4 years of age. Language Acquisition, 16, 36-66.

Holton, D., Mackridge, P., \& Philippaki-Warburton, I. (1997). A comprehensive grammar of the Modern Greek language. London: Routledge.

Hyams, N. (2002). Clausal structure in child Greek: a reply to Varlokosta, Vainikka and Rohrbacher and a reanalysis. The Linguistic Review, 19(3), 225-269.

Jaeger, T. F. (2008). Categorical data analysis: Away from ANOVAs (transformation or not) and towards logit mixed models. Journal of Memory and Language, 59(4), 434-446.

Johnson, V. E., de Villiers, J. G., \& Seymour, H. N. (2005). Agreement without understanding? The case of third person singular/s/. First Language, 25(3), 317-330.

Kouider, S., Halberda, J., Wood, J., \& Carey, S. (2006). Acquisition of English number marking: The singular-plural distinction. Language Learning and development, 2(1), 1-25.

Koulaguina, E., Legendre, G., Barrière, I., Menu, I., Sivakumar, E., \& Nazzi, T. (2018). Suffixal Subject-Verb Number Agreement: The Development of Comprehension in French-learning Toddlers from 30 to 36 Months. Poster presented at the Boston University Conference on Language Development, Boston, MA.

Legendre, G., Barrière, I., Goyet, L., \& Nazzi, T. (2010). Comprehension of infrequent subject-verb agreement forms: Evidence from French-learning children. Child Development, 81, 1859-1875.

Legendre, G., Culbertson, J., Zaroukian, E., Hsin, L., Barrière, I., \& Nazzi, T. (2014). Is children's comprehension of subject-verb agreement universally late? Comparative evidence from French, English, and Spanish. Lingua, 144, 21-39.

Leonard, L., \& Bortolini, U. (1998). Grammatical morphology and the role of weak syllables in the speech of Italian-speaking children with specific language impairment. Journal of Speech, Language, and Hearing Research, 41(6), 1363-1374.

Leonard, L., Caselli, M. C., \& Devescovi, A. (2002). Italian children's use of verb and noun morphology during the preschool years. First Language, 22(3), 287-304.

MacWhinney, B. (2000). The CHILDES project: Tools for analyzing talk (3rd ed.). Mahwah, NJ: Lawrence Erlbaum Associates.

Maslen, R. J., Theakston, A. L., Lieven, E. V., \& Tomasello, M. (2004). A dense corpus study of past tense and plural overregularization in English. Journal of Speech, Language, and Hearing Research, 47(6), 1319-1333.

Mastropavlou, M. (2006). The role of phonological salience and feature interpretability in the grammar of typically developing and language impaired children. (Doctoral dissertation, Aristotle University of Thessaloniki).

Mennen, I., \& Okalidou, A. (2007). Acquisition of Greek phonology: An overview. In S. McLeod (Ed.), The international guide to speech acquisition (pp. 398-407). Clifton Park, NY: Thomson Delmar Learning.

Miller, P. H. (1992). Clitics and constituents in phrase structure grammar. New York: Garland.

Montrul, S. A. (2004). The acquisition of Spanish: Morphosyntactic development in monolingual and bilingual L1 acquisition and adult L2 acquisition. Amsterdam, The Netherlands: John Benjamins. 
Morgan, G., Barrière, I., \& Woll, B. (2006). The influence of typology and modality on the acquisition of verb agreement morphology in British Sign Language. First Language, 26(1), 19-43.

Nazzi, T., Barrière, I., Goyet, L., Kresh, S., \& Legendre, G. (2011). Tracking irregular morphophonological dependencies in natural language: Evidence from the acquisition of subject-verb agreement in French. Cognition, 120(1), 119-135.

Nikolopoulos, D., \& Goulandris, N. (2000). The cognitive determinants of literacy skills in a regular orthography. In M. Perkines \& S. Howard (Eds.), New directions in language development and disorders (pp. 261-270). New York, NY: Plenum Publishers.

Pérez-Leroux, A. T. (2005). Number problems in children. In C. Gurski (Ed.), Proceedings of the 2005 Canadian Linguistic Association Annual Conference (p. 12). Retrieved from http://ling.uwo.ca/ publications/CLA-ACL/CLAACL2005.htm

Poeppel, D., \& Wexler, K. (1993). The full competence hypothesis of clause structure in early German. Language, 69, 1-33.

R Core Team. (2018). R: A language and environment for statistical computing. Vienna, Austria: R Foundation for Statistical Computing. http://www.R-project.org/

Ralli, A. (2002). The role of morphology in gender determination: evidence from Modern Greek. Journal of Linguistics, 40, 519-551.

Räsänen, S. H., Ambridge, B., \& Pine, J. M. (2016). An elicited-production study of inflectional verb morphology in child Finnish. Cognitive Science, 40(7), 1704-1738.

Redford, M. A., \& Diehl, R. L. (1999). The relative perceptual distinctiveness of initial and final consonants in CVC syllables. The Journal of the Acoustical Society of America, 106(3), 1555-1565.

Revithiadou, A., \& Lengeris, A. (2016). One or Many? In Search of the Default Stress in Greek. In J. Heinz, R. Goedemans, \& H. Van der Hulst (Eds.), Dimensions of Phonological Stress (pp. 231-262). Cambridge: Cambridge University Press.

Rice, M. L., \& Wexler, K. (1996). Toward tense as a clinical marker of specific language impairment in English-speaking children. Journal of Speech, Language, and Hearing Research, 39(6), 1239-1257.

Seiler, H. (1952). L'aspect et le temps dans le verb néo-grec. Paris: Belles Lettres.

Stephany, U. (1985). Aspekt, Tempus und Modalität: Zur Entwicklung der Verbalgrammatik in der neugriechischen Kindersprache (Language Universals Series, 4). Tübingen: Gunter Narr Verlag.

Stephany, U. (1997). The acquisition of Greek. In D. I. Slobin (Ed.), The Crosslinguistic Study of Language Acquisition, 4 (pp. 183-333). Hillsdale, NJ: Erlbaum. <https://childes.talkbank.org/access/Other/Greek/ Stephany.html>

Stephany, U., Voeikova, M., Christofidou, A., Gagarina, N., Kovačević, M., Palmović, M., \& Hrzica, G. (2007). Strongly inflecting languages: Russian, Croatian, and Greek. In S. Laaha \& S. Gillis (Eds.), Typological perspectives on the acquisition of noun and verb morphology. Antwerp Papers in Linguistics 112 (pp. 35-46). Antwerp: University of Antwerp.

Sundara, M., Demuth, K., \& Kuhl, P. (2011). Sentence-position effects on children's perception and production of English 3rd person singular -s. Journal of Speech, Language, and Hearing Research, 54, 55-71.

Theakston, A. L., Lieven, E. V. M., \& Tomasello, M. (2003). The role of the input in the acquisition of third person singular verbs in English. Journal of Speech, Language and Hearing Research, 46, 863-877.

Tsimpli, I. M. (1996). Functional categories and maturation: The prefunctional stage of first language acquisition. New York: Garland.

Tomasello, M. (2003). Constructing a language: a usage-based theory of language acquisition. Cambridge, MA: Harvard University Press.

Valian, V., Prasada, S., \& Scarpa, J. (2006). Direct object predictability: Effects on young children's imitation of sentences. Journal of Child Language, 33(2), 247-269.

Varlokosta, S. (2005). Eventivity, modality and temporal reference in child Greek. In: M. Stavrou \& A. Terzi (Eds.), Advances in Greek generative syntax: in honor of Dimitra Theophanopoulou-Kontou. Amsterdam:John Benjamins, 76, 217-240.

Varlokosta, S. (2011). The role of morphology in grammatical gender assignment: A psycholinguistic study in Greek. In A. Galani, G. Hicks \& G. Tsoulas (Eds.), Morphology and its Interfaces. (pp. 49-76). Amsterdam: John Benjamins. 
Varlokosta, S., \& Nerantzini, M. (2013). Grammatical gender in specific language impairment: evidence from determiner-noun contexts in Greek. Psychology: The Journal of the Hellenic Psychological Society, 20(3), 338-357.

Varlokosta, S., Vainikka, A., \& Rohrbacher, B. (1998). Functional projections, markedness, and "root infinitives" in early child Greek. The Linguistic Review, 15(2-3), 187-208.

Cite this article: Kenanidis P, Chondrogianni V, Legendre G, Culbertson J (2021). Cue reliability, salience and early comprehension of agreement: Evidence from Greek. Journal of Child Language 48, 815-833. https://doi.org/10.1017/S0305000920000628 